\title{
Synthesis, Structures, and Magnetic Properties of Metal-Coordination Polymers with Benzenepentacarboxylate Linkers
}

\author{
Xin-Yi Wang and Slavi C. Sevov* \\ Department of Chemistry and Biochemistry, University of Notre Dame, Notre Dame, \\ Indiana 46556
}

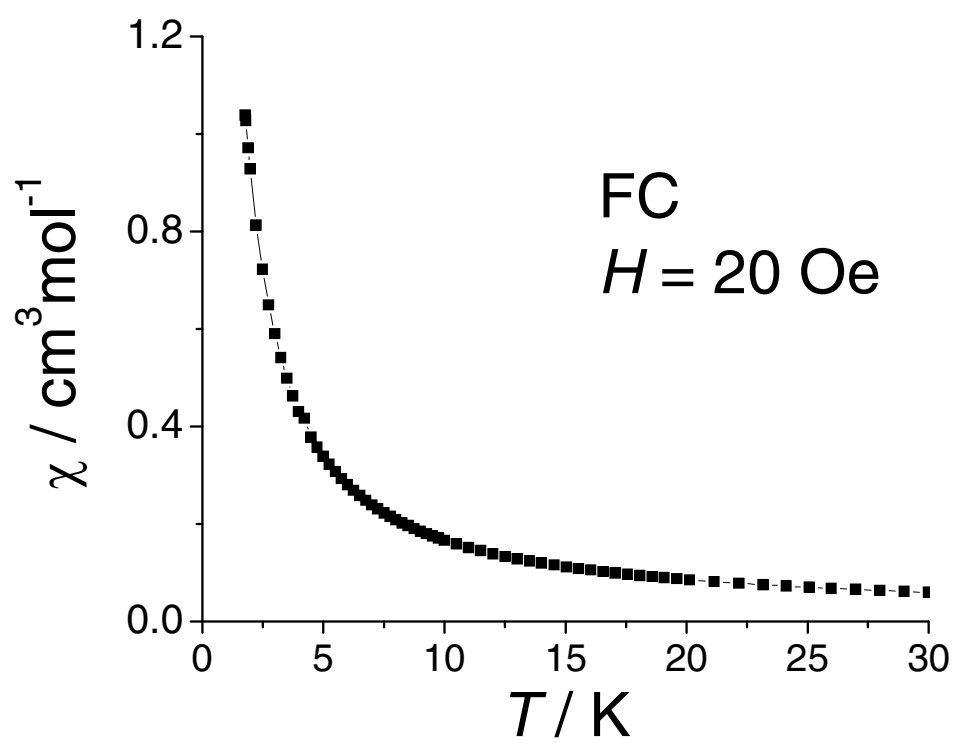

Figure S1. The FC curve for compound 3-Co under 20 Oe from 2 to $30 \mathrm{~K}$. 